UNIVERSIDADE DE BRASÍLIA

Departamento de Economia

\title{
Gastos e Spillover Effects: uma avaliação do programa RPS
}

João Carlos Nicolini de Morais

Brasília

2014 


\section{Gastos e Spillover Effects: uma avaliação do programa RPS}

Dissertação apresentada como requisito para a obtenção do título de Mestre em Economia pelo programa de PósGraduação em Economia da Universidade de Brasília.

João Carlos Nicolini de Morais

Orientador: Professor Doutor Christian Lehmann 


\title{
Gastos e Spillover Effects: uma avaliação do programa RPS
}

\author{
João Carlos Nicolini de Morais
}

Dissertação apresentada como requisito para a obtenção do título de Mestre em Economia pelo programa de Pós-Graduação em Economia da Universidade de Brasília

Aprovada por:

Professor Doutor Christian Lehmann (Orientador)

Professor Doutora Maria Eduarda Tannuri-Pianto (membro interno)

Professor Doutor Fábio Vaz (membro externo)

Brasília, 5 de dezembro de 2014 


\title{
Resumo
}

Programas sociais que estabelecem condicionalidades para o ganho de benefícios alcançaram grande popularidade nos últimos anos. O programa RPS (Reds de Protección Social) realizado na Nicarágua teve a adição de uma fase inicial com a avaliação de comunidades separadas em grupos controle e de tratamento. Apesar do desenho experimental para a avaliação do programa, não se deve desconsiderar a possibilidade da existência de efeitos indiretos sobre não-beneficiários ou mesmo sobre outros beneficiários. Tentamos destacar neste trabalho a possibilidade desse efeito entre as comunidades avaliadas. Com uma base de dados que indica a proximidade entre as localizações obtidas, relatamos spillover effects significantes e negativos para os gastos das famílias avaliadas. Dessa forma acreditamos gerar uma motivação para o aprofundamento da pesquisa sobre os efeitos do RPS entre as comunidades de avaliação.

Palavras-chave: RPS, Spillover Effects, Nicarágua, Experimentos Controlados, Conditional Cash Transfers

\begin{abstract}
Social Programs that condition their beneficits have attained great popularity in the recent years. The RPS program (Reds de Protección Social) carried out in Nicaragua had a preliminary avaliation phase in which communities were selected to treated and controlled groups. Although the avaliation had an experimental design, one must not neglect the possibilities of indirect effects on non-beneficiaries or even with other beneficiaries. We try to highlight the possibility of such an effect between the communitties avaliated in the program. With a data set that indicates the proximity of the localities obtained, we report significant and negative spillovers on the expenditure of the avaliated families. In this way, we believe that we generate a motivation for further research on the effects of RPS across villages.
\end{abstract}

Keywords: RPS, Spillover Effects, Nicaragua, Randomized Controlled Trials, Conditional Cash Transfers 


\section{Introdução}

É inegável a popularidade dos Conditional Cash Transfers (CCTs), programas tais como o programa Bolsa Família no Brasil, o Prospera ${ }^{1}$, também conhecido como Progresa, no México, e o Familias en Acción na Colômbia - todos são relatados sucessos no documento do Banco Mundial Poverty reduction and growth: virtuous and vicious circles (2006). Há também outros destaques, como o Chile Solidario, no Chile, que é um outro sucesso relatado em Palma e Urzúa (2005) e veio a se somar a medidas mais inclusivas dos governos democráticos no país, após o fim da ditadura. Em verdade, a maior parte dos países da América Latina têm experiências com programas similares, confome o relatório Conditional Cash Transfers: Reducing Presentand Future poverty (2010), do Banco Mundial. Todos os programas mencionados acima tiveram impacto sobre o combate à miséria $\mathrm{e}$ geraram a promoção de incentivos ao aumento de capital humano nestes países, no que os programas condicionam o pagamento dos benefícios a uma determinada contrapartida das famílias. A mais comum sendo as matrículas dos filhos e o monitoramento das frequências nas escolas para a manutenção do benefício.

Segue que aqui, neste trabalho, faremos uma análise de um desses programas: o Reds de Protección Social, à frente simplificadamente referido como RPS. O programa teve a particularidade, similar ao Progresa no México, de ter sido desenhado como um programa com grupos de controle e de tratamento, assinalados aleatoriamente. O período de análise do programa foi de dois anos e rendeu relatórios como o de Maluccio e Flores (2004) e Maluccio (2005), e trabalhos como o de Gitter e Barham (2009,

\footnotetext{
1 Prospera é o terceiro nome pelo qual o programa mexicano de CCTs é nomeado. Antes o programa já foi conhecido como Oportunidades e, em sua fase de avaliação, no qual se baseiam os estudos experimentais do programa, o programa era nomeado Progresa. Na maior parte dos trabalhos referenciados neste presente texto, o programa mexicano é discutido com o nome de Progresa.
} 
2013) e Gitter e Caldes (2009), contudo não é um programa tão explorado como o experimento mexicano ${ }^{2}$. No relatório de Maluccio e Flores (2004) acha-se os primeiros resultados, através de uma especificação econométrica de double differences ou, pelo nome mais popular, diff-in-diff; neste trabalho procuraremos complementar estes resultados iniciais compreendendo a possibilidade de spillovers no programa, a julgar pela proximidade entre as vilas brevemente destacada no relatório de Maluccio e Flores (2004) e a constatação pelos dados observados.

Não há muitos artigos que testam para a possibilidade de spillovers em programas como o RPS - e menos ainda entre as localidades aleatorizadas na avaliação dos programas. Alguns trabalhos que podem ser citados são os de Bobonis e Finan (2009) e Angelucci e De Giorgi (2009), para spillovers dentro das comunidades, e Gignoux (2009) e Bobba e Gignoux (2010), que testam para o mesmo efeito entre as comunidades. Mas é no trabalho de Miguel e Kremer (2004) que buscamos a referência para o teste experimental deste trabalho, embora não seja um trabalho que avalie um CCT. No artigo são avaliados os spillovers de tratamento sobre alunos dentro e fora das escolas (considerando distâncias em um intervalo de 0 a $6 \mathrm{~km}$ ). Devido ao desenho do programa RPS em sua fase de avaliação e a proximidade entre as localizações, entendemos um amparo para a execução de um teste similar.

Neste trabalho temos somente a pretensão em trabalhar experimentalmente com os dados do programa RPS. À frente, verificaremos que há razão para o teste de spillovers e que esses mesmos resultam em um impacto significante e negativo sobre os gastos, sobretudo nos gastos com alimentos -- registrado pelo efeito do número de tratados na equação econométrica. Esperamos com

\footnotetext{
${ }^{2}$ Uma procura no site "Google Scholar" e no site JSTOR revela uma diferença ampla de resultados e citações entre os dois programas, chegando a uma diferença de mais dez vezes no número de menções ao programa mexicano em ambas procuras.
} 
esse resultado obter uma descrição dos efeitos do programa em sua medida mais ampla.

Seguimos à frente a detalhar a literatura que constata a possibilidade de spillovers em experimentos controlados, na seção 2, e a explicar características do programa RPS na seção 3 juntamente de detalhes sobre os dados de localização e a condição da base de dados diante das localizações obtidas. Na seção 4 apresentaremos o modelo econométrico de análise e, em seguida, os resultados são discutidos na seção 5 . Na seção 6 , finalizamos com a conclusão e as motivações geradas pelos resultados obtidos com o método experimental. Ainda providenciamos um apêndice, em três partes. A primeira parte contém regressões adicionais às apresentadas na seção de resultado e uma figura descrevendo a variabilidade da variávelchave do teste experimental deste trabalho; a segunda contém tabelas em que avaliamos algumas variáveis no baseline, por termos que usar um número restrito de Comarcas $^{3}$; e a terceira contém dois mapas com as localizações de tratamento e de controle para referenciar adequadamente as localizações.

\section{CCTs e Experimentos Controlados}

Randomized controlled trials, o que será chamado à frente de experimentos controlados, ganharam popularidade por possuírem mais confiabilidade em comparação com estudos não-experimentais, devido a dificuldade de se produzir estudos controlados com as variáveis sociais e econômicas.

\footnotetext{
${ }^{3}$ Comarcas são regiões administrativas na Nicarágua e em outras regiões de língua espanhola - no caso da Nicarágua, trata-se de uma região em um nível abaixo da municipalidade. No programa RPS foram usadas Comarcas Censales, que não necessariamente batem, em localização, com as Comarcas administrativas típicas. Trataremos de mais detalhes sobre a condição das localizações à frente. Evitaremos o uso do nome no restante trabalho, referindo-se às regiões como como "comunidades" ou "localizações".
} 
A revista The Economist ${ }^{4}$ relatou em 2008 a popularização em se estudar e fazer programas controlados, pois, através desses programas, seria possível a obtenção de dados mais robustos. Porém, programas controlados não estão completamente imunes à existência de vieses, a depender do método usado nas análises produzidas e há uma literatura para estabelecer esse fato.

Nessa literatura são incluídos trabalhos como o de Duflo e Saez (2003), que estimaram o efeito de peer effects, dentro de um programa controlado, de departamentos de uma universidade para a aceitação de um plano de aposentadoria - o trabalho acha efeitos próximos entre não-convidados e convidados para o programa em um mesmo departamento. Katz, Kling e Liebman (2001) examinam mudanças em vizinhanças de Boston sobre famílias que receberam vouchers através de uma loteria. E relacionado a esses estudos, embora se trate da análise de um quase-experimento e não de um programa controlado propriamente, está o de Sacerdote (2001), que produziu resultados interessantes ao usar a atribuição aleatória de colegas de dormitório na Universidade de Dartmouth. Os peer effects verificados tiveram impacto no resultado acadêmico dos alunos e em decisões de se juntar a determinados grupos sociais.

No caso dos CCTs que são avaliadas em programas controlados, conforme a literatura recente, os programas devem afetar os tratados diretamente, mas, também, indiretamente aqueles que não participam ou não são beneficiados pelo programa em uma determinada proximidade -- isto é, neste caso devem existir efeitos indiretos operando com as transferências. Os mecanismos citados pelos quais os não-elegíveis acabam sendo afetados são variados e são reportados, resumidamente, em Lehmann (2010). Daremos um pequeno paranorama a seguir.

\footnotetext{
4"Control Freaks" da revista The Economist (12 de Julho de 2008).
} 
Em escolaridade, essas externalidades podem ocorrer pela informação obtida em workshops existentes em vários programas no formato de CCTs, em igrejas, festividades ou por "famílias estendidas"5; pelo efeito do lado da oferta, ao que os programas de CCTs podem oferecer mais professores e estrutura antecipando o aumento da frequência escolar, mas também afetando inelegíveis dessa forma; com as transferências e o aumento da demanda dos eleitos ao programa, a renda dos não elegíveis ao programa pode aumentar através de efeitos multiplicativos e permitir um maior gasto com educação. Nota-se, também, conforme Gignoux (2009), que as externalidades ocorrem não somente dentro da vila, mas entre vilas. Isso poderia ocorrer através das "famílias estendidas" presentes em vilas adjacentes. Assim como pelo fato de famílias tratadas terem filhos frequentando escolas em outras vilas ou pela antecipação das famílias pertencentes a vilas que não participam do programa, mas que têm a expectativa, em um futuro próximo, de participar.

Logo, acreditamos que os métodos mais comuns para a avaliação de efeitos diretos, como o ATE (Average Treatment Effect) ${ }^{6}$, podem produzir resultados viesados para a análise em programas como o RPS. De fato, em um programa como o RPS em que podemos verificar a adjacência entre as localizações do programa - vide apêndice com mapas - e considerando a existência de outros estudos, como os de Bobba e Gignoux (2010) e Miguel e Kremer (2004), nos surge a suspeita para executar um teste quanto à presença de efeitos indiretos entre as comunidades.

\footnotetext{
${ }^{5}$ Redes pré-existentes de famílias que atravessam gerações, com integrantes que moram na mesma casa ou nas proximidades de uma família (tratada) -- procuraria-se, por essa ideia, externalidades dentro de uma vila ou vizinhança. Mais relevantes para o assunto de spillovers interregionais, seriam famílias "estendidas" que contém integrantes em vilas ou comunidades adjacentes de uma família tratada pelo programa.

${ }^{6} \mathrm{O}$ ATE pode ser definido através da equação: $\operatorname{ATE}=E\left(Y_{i} \mid T_{i}=1\right)-E\left(Y_{i} \mid T_{i}=0\right)$. Onde $Y_{i}$ representa a variável de resultado e $T_{i}$ representa uma variável binária de assinalamento aleatório ao status de tratado ou de controle. Neste trabalho daremos exemplos de vieses desta estimativa à frente.
} 


\subsection{Spillovers Dentro das Comunidades e os Mecanismos que Impactam o Consumo}

Uma condição para que seja estimado o ATE sem vieses é o SUTVA (Stable Unit Treatment Value Assumption), de acordo com Rubin (1986). Essa condição compreende que o efeito do tratamento é não-viesado se o resultado obtido com o objeto tratado não depende do assinalamento de outros objetos ao tratamento. Se há a presença de efeitos indiretos entre tratados e não-tratados, por exemplo, há falha do SUTVA. Trata-se de uma condição razoável em experimentos de pequena escala ou quando não há razão para acreditar que existem outros efeitos indiretos - e.g. ausência de mercados.

Conforme Angelucci e Giorgi (2009), efeitos indiretos que violam SUTVA se tornam mais prováveis quando o experimento controlado (um CCT em sua fase de avaliação) atinge uma grande parte da população, produz transferências grandes para essa população, relaxa algumas restrições (como as transferências monetárias que substituem a ausência de mercados de crédito formais), opera em áreas em que tratados e não-tratados estão suficientemente perto e já atua há algum tempo.

$\mathrm{Na}$ avaliação do Progresa de Angelucci e Giorgi (2009) há a estimativa do ITE (Indirect Treatment Effect). Isto é, se não há efeitos indiretos relevantes entre as comunidades, para averiguar o ITE (que ocorre dentro das comunidades avaliadas) poderia usar-se a equação (1) para estimar efeitos indiretos: 


$$
I T E=E\left(Y_{i} \mid T_{i}=1, N P_{i}=1\right)-E\left(Y_{i} \mid T_{i}=0, N P_{i}=1\right)
$$

Onde $Y_{i}$ é a variável de resultado avaliada, $T_{i}$ representa o status de tratamento assinalado ao nível da comunidade e $N P_{i}$ representa o status de "não-pobre" $\left(T_{i}, N P_{i} \in[0,1]\right)$ - se $N P_{i}$ assume o valor 1 , trata-se da observação de um "não-pobre" -, os não-elegíveis dentro das comunidades avaliadas e com características similares. A equação assume que os "nãopobres" em comunidades de controle são um bom contra-factual para os "não-pobres" de comunidades tratadas. No caso do RPS, não observamos por enquanto como executar testes similares com os dados do programa justamente por não termos um grupo de não-beneficiados com características similares nos grupo de controle e de tratamento. Por essa razão nos limitaremos à frente aos spillovers entre as comunidades.

Entre as razões investigadas em Angelucci e Giorgi (2009) para a existência de spillovers que aumentam o consumo de "não-pobres", há possíveis 1) efeitos no mercado de trabalho, como o efeito da condicionalidade da frequência escolar: com a queda do uso da mão-de-obra infantil, poderia existir um aumento de salários de equilíbrio ou aumento da oferta de trabalho de "não-pobres", o que afetaria indiretamente o seu consumo; 2) aumento de preços em comunidades tratadas em conjunto com o aumento das vendas de produtos por famílias não-pobres ou o simples aumento das vendas das mesmas; 3 ) através de mercados informais de crédito, onde familiares ou conhecidos locais suprem a falta de um mercado formal de crédito.

Compreendemos que há o cumprimento de algumas dessas condições para a violação do SUTVA no RPS, como a grande proporção de pessoas que receberam $O$ benefício em comunidades tratadas e $o$ tamanho das 
transferências. Mas não julgamos crível que transferências monetárias sejam a razão do spillover no RPS, que é a explicação usada em Angelucci e Giorgi (2009). Em detalhe, há razão para acreditar em efeitos negativos pelos resultados relatados à frente.

Se há efeitos entre tratados e controlados entre as comunidades, a estimativa (1) é incapaz de identificar os spillovers adequadamente. Ou seja, como os efeitos devem ter o mesmo sinal (o spillover dentro e o entre comunidades), o spillover identificado seria um limite inferior se positivo; ou superior, se negativo. Se os efeitos de spillover são próximos (sobre não-beneficiários em vilas tratadas e sobre os controlados em vilas adjacentes), os efeitos também podem não ser identificados mesmo quando os spillovers estão presentes.

Como já foi dito, há motivos para acreditar em spillovers entre as comunidades no RPS, o que será detalhado mais à frente. Porém não há uma evidência clara de que podemos generalizar o caso do RPS ${ }^{7}$.

Não há, também, uma ideia precisa e coerente de como os spillovers operam no programa RPS por enquanto, tal como em Angelucci e Giorgi (2009). No entanto acreditamos que os resultados descritos neste trabalho apontam para novos estudos desses mecanismos no RPS. Detalharemos agora o programa e a base de dados.

\footnotetext{
${ }^{7} \mathrm{Na}$ amostra que usamos, há mais comunidades em um raio de $5 \mathrm{~km}$ do que no Progresa mexicano - 17 de $33(51,5 \%)$ comunidades têm pelo menos uma outra comunidade nesse raio, quando no Progresa são 40\%, de acordo com Bobba e Gignoux (2010). Há também o tamanho relativamente grande de beneficiados nas comunidades tratadas e, possivelmente, os efeitos particulares de crises que afetaram a região (Maluccio (2005)) e que talvez tornem o caso do RPS particular. Trata-se de um indício qualitativo de que devem existir spillovers.
} 


\section{O Programa RPS}

O programa RPS foi inspirado no Progresa mexicano em sua fase de avaliação, com a estruturação da avaliação incluindo comunidades de controle e de tratamento. Nos beneficiamos aqui de Maluccio e Flores (2004) para descrever o programa, que foi avaliado em detalhe por esses autores. Delinearemos os dados básicos do programa e tentaremos, assim, não nos estender além do necessário.

O programa ocorreu durante o período de 2000-2002 nos departamentos de Madríz e Matagalpa, no norte da Nicarágua. Tratam-se de regiões que, durante um período em que tanto a pobreza rural e urbana estavam declinando nacionalmente, tiveram aumento dos níveis de pobreza, de acordo com o relatório do Banco Mundial citado por Maluccio e Flores (2004), Nicaragua Poverty Assessment: Raising Welfare and Reducing Vulnerability (2003).

O programa, conforme o Progresa mexicano, foi aleatorizado em grupos de tratamento e controle, com a particularidade de que as comunidades foram divididas em sete estratificações calculadas a partir de um índice de marginalização presente no documento de Arcia $(1999)^{8}$, onde, em cada municipalidade, seis Comarcas Censales $^{9}$, conforme determinadas pelo INIDE (Instituto Nacional de Información de Desarrollo), foram randomizadas entre o grupo de controle e de tratamento do programa, através de um

${ }^{8} \mathrm{O}$ índice foi calculado a partir das pesagens de 4 variáveis (os pesos, em percentuais, entre parênteses): tamanho médio de família (10\%), percentual dos sem água encanada (50\%), o percentual dos sem latrina (10\%) e o percentual de iletrados acima de 5 anos. Através desse índice definiram-se as Comarcas que iniciariam a participação no programa. As Comarcas de prioridade 1 e 2 , presentes na base de dados, justamente as mais pobres, foram as primeiras participantes. Não tivemos acesso ao documento e, portanto, o citamos indiretamente aqui, através de Maluccio e Flores (2004).

${ }^{9} \grave{A}$ frente voltamos a nos referir às regiões como "comunidades" ou "localizações". Aqui só voltamos ao nome de Comarcas Censales para deixar claro que são regiões definidas pelo órgão estatístico INIDE. 
sorteio: retirou-se às cegas, sem reposição, em sete sorteios para cada uma das estratificações, seis bolas para atribuírem status de controle ou de tratamento da comunidade. Assim, somou-se um total de 42 comunidades para o experimento, com 21 no grupo de controle e 21 no grupo de tratamento.

O programa seguiu a racionalidade comum dos CCTs, não só buscando um alívio da pobreza através das transferências imediatas, mas também uma solução para a pobreza no longo prazo, ao condicionar os pagamentos. Em detalhe, o programa pagava o bono alimentario mensalmente, condicionando as famílias eleitas para o programa a frequentarem workshops educativos e levarem seus filhos menores de 5 anos para atendimentos preventivos em saúde; o bono escolar, condicionado à matrícula e à frequência escolar, e o mochila escolar, para o pagamento de material escolar e condicionado à matrícula -- todas essas duas últimas transferências para crianças que não completaram o $4^{\circ}$ ano da escola primária. Como incentivos aos professores e às escolas pelo número de alunos adicionais, houve também as transferências bono a la oferta, que eram transferências captadas pelas famílias e repassadas aos professores pelas famílias eleitas ao programa. Nesta última transferência, os professores ficavam com uma metade da transferência e as escolas com a outra metade. Conforme Maluccio e Flores (2004), houve monitoramento da entrega das transferências aos professores, mas não houve monitoramento do que foi feito com este benefício após a entrega.

Somente o repasse para alimentação representava em média $13 \%$ do gasto anual das famílias focalizadas para a avaliação. Com um filho na escola, esse percentual subia para $21 \%$. Um outro aspecto a ser observado é a escala do programa: em seu momento de avaliação, o RPS detinha um orçamento de 11 milhões, o equivalente a $0,2 \%$ do PIB da Nicarágua até então. 
O programa seguiu por dois anos, quando, em verdade, a expectativa inicial era seguir com o experimento durante um ano e, após o período, incorporar as comunidades do grupo de controle aos benefícios do programa, mas, conforme Maluccio e Flores (2004), devido a uma auditoria sofrida pelo goveno no período, esse processo foi atrasado e a expansão só ocorreu em 2003. Segue ainda, diferentemente do Progresa mexicano, que o RPS não ajustava as suas transferências à inflação. Após dois anos, o valor real das transferências somou uma perda de $8 \%$. Mas, conforme reportam Maluccio e Flores (2004), este efeitos devem ser pequenos.

Quanto aos dados propriamente usados por Maluccio e Flores (2004), o que se possui é uma amostra representativa das comunidade - e que são os dados deste trabalho. Em cada comunidade, foram selecionadas 42 famílias para compor a amostra. As comunidades, porém, não possuem tamanho similar: amostra possui fatores de expansão para dar conta da representatividade da amostra para cada comunidade. Em Maluccio e Flores (2004), os pesos (fatores de expansão) são ignorados na análise, pois não mudam significantemente os resultados. Mas as comunidades são representadas em suas populações somente quanto pesadas adequadamente. No desenho do programa, $6 \%$ das famílias no conjunto das 42 comunidades foram consideradas inelegíveis. Cabe também relatar que nas comunidades assinaladas ao tratamento algo logo abaixo de $90 \%$ da população das comunidades recebeu o benefício. Dada essa proporção e a predominância de um alto nível de pobreza na região, menos de $5 \%$ da população pobre foi excluída do programa (undercoverage do programa) e $15 \%$ de não-pobres receberam o benefício (leakage).

Ainda, Maluccio e Flores (2004) nos reportam que o programa sofreu alguns problemas nas classificações e reentrevistas de participantes. No primeiro follow up do programa, em 2001, 91,9\% das famílias foram reentrevistadas e, em 2002 , algo um pouco acima de $88 \%$, incluindo um conjunto de famílias 
que foi classificada erroneamente no grupo de controle. Conforme o relatório, 37 famílias foram classificadas erroneamente, 6 formulários desapareceram e que, pelo menos a após a inclusão das 37 famílias classificadas erroneamente na parcela dos que não foram reentrevistados, os níveis percentuais de atrição entre o grupo de controle e de tratamento se aproximaram. Através de regressões probit não reportadas, os autores alegam que a atrição é não-aleatória, que as famílias perdidas no follow up possuem condições, em média, piores do que as famílias da amostra; com regressões que incluem a amostra com famílias que não foram entrevistadas em todos follow ups e testando alternativamente com efeitos fixos (e sabendo que o efeito reportado pelos autores é maior para os mais pobres), o relatório julga que atrição não é um grande problema.

Os resultados apresentados no relatório de Maluccio e Flores (2004) são sob um painel balanceado, dado o que já foi mencionado sobre a diferença entre o número de entrevistados nos follow ups, essa seria a opção conservadora para relatar os reais efeitos do programa, que podem ser maiores. Ainda, os resultados do relatório são reportados com a atribuição aleatória para a comunidade e há, assim, a inclusão de não-participantes dentro das comunidades tratadas nos resultados declarados como tratados. Contudo as taxas de participação no programa são bastante altas. Logo, não há uma grande diferença entre os dois métodos.

Maluccio e Flores (2004) reportam melhoras significantes entre o grupo controle e o de tratamento, usando um double diferences ou, mais comumente conhecido, diff-in-diff para avaliar os efeitos do programa no período de 2000-2001 e 2001-2002. Os autores estressam o valor do programa ser controlado devido a uma crise ocorrida no período -- de outra forma, seria bastante difícil avaliar os efeitos do programa adequadamente. Obtemos alguns detalhes em Maluccio (2005) quanto ao período da crise, que é relacionada a uma estiagem e à queda de preços de café coincidindo com o período do programa. Conforme é relatado, houve um impacto maior 
do programa sobre as comunidades produtoras de café. Todas as comunidades ligadas à produção de café se encontram na região de Matagalpa, onde se concentra, das 42 comunidades avaliadas, 35 comunidades.

Quanto à possibilidade de efeitos indiretos amparados em um possível comportamento estratégico, observamos que o relatório diz que pelo menos $50 \%$ dos não-beneficiários de comunidades de controle não conheciam o programa. O indicador de conhecimento do programa, que ficou disponível a partir de 2002, demostra que daqueles que conheciam o programa, aproximadamente três quartos responderam questões sobre o programa corretamente e pelo menos um terço detinham conhecimento de aspectos específicos do programa.

\subsection{A Base de Dados usada}

Neste trabalho usamos a localização de 33 comunidades das 42 comunidades originais ${ }^{10}$. As informações foram obtidas com dificuldade $e$ demora esperadas e ainda são limitadas até o momento. A base de dados usada é a que está disponível no site do IFPRI ${ }^{11}$ para o programa RPS somada à construção do número de comunidades e do número de comunidades tratadas (dentro de uma distância $d$ da variável observada ${ }^{12}$ ) com os novos dados de localização. Assim, trata-se de uma base específica para este trabalho.

\footnotetext{
${ }^{10}$ As Comarcas estudas são pequenas comunidades com poucos habitantes e não muitas referências, na internet, para as suas localizações. Em média, para se ter uma ideia do quão pequena podem ser essas Comarcas, na amostra usada neste trabalho, são 37,7 famílias por Comarca. Assim, não houve como obter os dados de localização de forma simples e direta.

${ }^{11}$ Segue um link, na bibliografia deste trabalho, para a base disponível na internet do IFPRI. 12 Para cada observação, construiu-se um número de vilas tratadas e um número total de vilas, em um raio (distância) $d$ que varia de 5 a $30 \mathrm{~km}$.
} 
Não houve alternativa fácil e direta para a obtenção dos dados: os dados não são facilmente encontrados na internet. Tratam-se de pequenas comunidades rurais e de poucos habitantes. Houve a tentativa de contatar outros pesquisadores que trabalharam com os dados do RPS, que demonstraram não possuir tais localizações ${ }^{13}$. Mas obteve-se um contato frutífero com a embaixada da Nicarágua em Brasília ${ }^{14}$ e que eventualmente trouxe o contato de um funcionário do MAGFOR (Ministerio Agropecuario y Forestal) ${ }^{15}$ da Nicarágua. Com esse funcionário foi obtida a relação das localizações usadas neste trabalho.

Por se tratar de uma base diferente das 42 comunidades originais, devemos comparar novamente as variáveis iniciais dos grupos de controle e de tratamento. No apêndice demonstramos o resultado com os dados coletados no baseline, no ano de 2000, e anteriormente ao início do programa, no censo pré-RPS. Na Tabela I cruzamos a nossa amostra com os dados do censo e verificamos se existem diferenças significantes entre o grupo de controle e de tratamento. Depois, na Tabela II, usamos os dados coletados entre Agosto e Setembro de 2000, ao início do programa - essa tabela foca em gastos. Dentre as variáveis observadas, há algumas diferenças significantes estatisticamente, mas em sua maioria são diferenças pequenas, mas há duas diferenças grandes verificadas nos gastos em saúde e no tamanho das propriedades em metros quadrados. No apêndice fazemos uma discussão mais uma discussão das variáveis nas tabelas e as detalhamos.

\footnotetext{
${ }^{13}$ Contatou-se John Maluccio, que foi solícito em compartilhar alguns dados, mas não se obteve as localizações. Entramos em contato com outros responsáveis da fase de avaliação do RPS e que também não possuíam as localizações.

${ }^{14}$ Devo aqui um agradecimento às orientações de Marvin Ortega, funcionário da embaixada da Nicarágua, e que trouxe esperanças para a obtenção dos dados desta pesquisa.

${ }^{15}$ Aqui segue um agradecimento imenso a Isidro Salinas, o funcionário responsável pela obtenção dos dados.
} 
Em particular, também não usamos os não-participantes dentro das comunidades tratadas em nossa base ${ }^{16}$.

\subsubsection{A localização das Comunidades}

Maluccio e Flores (2004) comentam a proximidade das comunidades brevemente, notando que as comunidades de controle e de tratamento podem se encontrar em localizações adjacentes. Por essa referência, pela literatura citada e pelos dados obtidos, naturalmente surge o interesse em se testar os possíveis efeitos de spillovers não considerados em estudos prévios do RPS.

Com paciência, foram obtidas as localizações de 33 comunidades através de e-mails e planilhas enviadas por um local na Nicarágua, mas não há ainda uma certeza plena e correta da localização das comunidades ${ }^{17}$, porém as localizações batem com os municípios do departamento de Madriz, Yalagüina e Totogalpa, e dos de Matagalpa, que são Ciudad Darío, El Tuma - La Dalia, Terrabona e Ésquipulas, conforme relatado no documento de Overview dos dados do RPS.

Dessa maneira foi obtida uma amostra não-balanceada de comunidades de controle e de tratamento: 14 comunidades são de tratamento e 19 são de controle.

\footnotetext{
16 Os resultados observados em regressões não reportadas diferem pouquíssimo.

${ }^{17}$ As localizações das 33 comunidades foram obtidas através de uma série de e-mails com Isidro Salinas. As localizações foram obtidas de modo consultivo e repassadas a mim por email. Os dados são os usados pelo Ministério Agropecuário e de Floresta (MAGFOR). Os dados não são os das Comarcas Censais, mas o das administrativas.
} 
Os dados foram obtidos em UTM $^{18}$ (Universal Transverse Mercator) e em latitudes e longitudes. Porém as distâncias foram calculadas em UTM ${ }^{19}$ e através de uma distância euclidiana simples ${ }^{20}$. Dessa forma foi possível calcular uma matriz de distâncias entre as comunidades. Em um raio de $5 \mathrm{~km}$ mais de $50 \%$ das comunidades têm pelo menos outra adjacente. Com $3 \mathrm{~km}$, obtem-se $30 \%$ das comunidades com pelo menos uma vila adjacente ${ }^{21}$. Essa proximidade mais a proporção da população beneficiada nas comunidades tratadas é o indício para o teste deste trabalho.

\section{Método de Análise}

A avaliação mais comum do programa RPS tem sido através de um Average Treatment Effect (ATE). Considerando que os grupos de controle são contrafactuais adequados, de forma simplificada podemos expressar esse efeito na seguinte equação econométrica:

$$
Y_{i}=\beta_{0}+\beta_{1} T_{i}+\varepsilon_{i}
$$

\footnotetext{
${ }^{18}$ Confome o site NOAAHistory, o sistema foi inventado por engenheiros americanos na década de 40. Trata-se de um sistema que gera uma projeção em duas dimensões da superfície da terra, em coordenadas cartesianas.

${ }^{19}$ Inicialmente haviam mais dados em UTM, contudo, pela imprecisão verificada em mapas, julgou-se adequado eliminar uma localização, o que retornou ao conjunto das localizações, tanto em UTM como no sistema típico de latitude e longitudes, a números iguais. Mas mantemos, devido ao fato das mudanças serem mínimas dentro das distâncias usadas, as distâncias calculadas originalmente em UTM.

${ }^{20} \mathrm{~A}$ distância foi calculada por uma fórmula simples, através das distância euclidianas, e, assim, a fómula expressa para medir a distância entre duas posições foi a seguinte: $D_{12}=\frac{\sqrt{\left(\left(E_{1}-E_{2}\right)^{2}+\left(N_{1}-N_{2}\right)^{2}\right)}}{1000}$. A ponderação por 1000 nos dá o resultado em $\mathrm{km}$. Através dessa fórmula foi possível obter uma matriz de distâncias e estabelecer as distâncias entre as Comarcas. Trata-se de uma fórmula simples, mas tentar o cálculo por uma fórmula mais sofisticada, através de uma conversão das coordenadas e o uso da distância geodésica, alterariam pouco os resultados dentro de um raio de distâncias pequeno, como os de 10, 15 ou $30 \mathrm{~km}$. Portanto nos mantemos com as distâncias calculadas através da fórmula acima. Contudo, há a limitação de que não consideramos obstáculos naturais (como montanhas, rios e vales) ou de redes de transporte. Conforme Bobba e Gignoux (2009), esses problemas podem introduzir um viés de atenuação para as estimativas calculadas e erros de medida para as características das regiões adjacentes.

${ }^{21}$ Acha-se alguma diferença no número de tratados ao redor das comunidades, também. Em média, há mais comunidades tratadas próximas de outras tratadas do que de comunidades de controle.
} 
Onde $Y_{i}$ representa a variável de resultado; $T_{i}$ representa uma variável binária de assinalamento aleatórioao status de tratado ou de controle $\left(T_{i} \in[0,1]\right)$, onde 1 se refere à atribuição de tratamento e 0 à de controle; $\beta_{1}$ representa o efeito do tratamento. $\beta_{0}$ é o intercepto da equação e $\varepsilon_{i}$ são os resíduos da equação econométrica. Subtraindo as esperanças condicionais deixamos o efeito mais claro:

$$
E\left(Y_{i} \mid T_{i}=1\right)-E\left(Y_{i} \mid T_{i}=0\right)=\beta_{1}
$$

$\beta_{1}$ só é capaz de representar um efeito de tratamento não-vieasado a depender da condição de não-violação do SUTVA. A esperança condicional do objeto tratado em (3) não pode depender do tratamento recebido por outros objetos.

Sob a violação da SUTVA, há efeitos indiretos e (3) se torna viesado. Neste trabalho temos suspeita da violação dessa condição, a julgar pela proximidade entre as localizações e a escala na qual foi implementado o programa RPS. Poderíamos, então, testar efeitos de densidade de unidades tratadas. Porém, para estimar esses efeitos poderíamos encontrar problemas na especificação econométrica. Se controlássemos somente a presença de tratados a uma distância $d$, nossas estimativas provavelmente sofreriam um problema de endogeneidade. Isto ocorreria por não controlarmos pela densidade da população a essa mesma distância: o número de tratados deve ser correlacionado com a densidade e, sem o controle da densidade, haveria correlação com os resíduos da regressão. Por exemplo, uma variável como o gasto deve ser claramente afetada por uma região de maior densidade e incorreríamos em um erro na especificação se não controlássemos para o efeito da densidade total. 
Miguel e Kremer (2004) fazem uso dessa ideia. Se controlarmos a densidade total a uma distância $d$, o número de tratados é exógeno e aleatório. Há assim uma forma de estimar os spillovers pela presença de tratados a uma distância $d$ das localizações participantes do programa. Para facilitar a compreensão da ideia, podemos colocar de uma forma mais explícita: se é controlada a densidade, o número de tratados é aleatório porque a assinalação ao status de tratamento foi aleatória.

Em nosso trabalho, por uma opção em demonstrar a possibilidade de grandes impactos em spillovers, optamos em usar o número de comunidades tratadas em uma proximidade $d$. Então, adicionamos em (2) o número total de comunidades tratadas e o número total de comunidades na distância $d$. Abaixo segue a equação econométrica que usamos para estimar os spillovers:

$$
Y_{i}=\beta_{0}+\beta_{1} T_{i}+\varphi_{d} N_{d i}^{T}+\theta_{d} N_{d i}+X_{i}+\varepsilon_{i t}
$$

Usa-se a especificação acima em (4) para as regressões observadas à frente neste estudo, considerando os pesos dos fatores de expansão da amostra os resultados são estimados de cross-sections dos anos de 2001 e de 2002. $Y_{i}$ é a variável independente de resultado; $T_{i}$ é a variável de tratamento, atribuída aleatoriamente às comunidades, da forma descrita em (2); $N_{d i}$ é o total de comunidades dentro da avaliação do programa RPS, sejam pertencentes ao grupo de controle ou ao grupo de tratamento, dentro de uma distância $d$ da localização a qual pertence a família da observação na variável de resultado. Podemos expressar esse total da seguinte maneira $N_{d i}=$ 
$N_{d i}^{T}+N_{d i}^{C}$, onde $N_{d i}^{C}$ é o total de comunidades de controle e $N_{d i}^{T}$ é o total de comunidades tratadas dentro da mesma distância $d . X_{i}$ representa um vetor de variáveis que se encontravam com médias significantemente diferentes no baseline e logo não-balanceadas entre os grupos de tratados e controlados ${ }^{22}$. O subscrito $i$ refere-se à identificação da observação da família.

O efeito que buscamos é o spillover que está no coeficiente $\varphi_{d}$. Na equação, os efeitos independentes de densidade são capturados pelo termo $\theta_{d}$ de forma a tornar as estimativas do coeficiente $\varphi_{d}$ exógenas, conforme já foi expresso.

\section{Resultados}

Conforme a especificação determinada na última seção, testa-se o efeito dos spillovers sobre os gastos. Relatamos somente os gastos totais com alimentos e o efeito na participação dos alimentos no gasto total das famílias. No Apêndice I relatamos alguns resultados adicionais de interesse. Há também o fato de que escolhemos reportar os resultados somente com os participantes dentro das comunidades tratadas. $A$ adição dos nãoparticipantes não alteram em muito os resultados.

Segue que os testes reportados - e em todos não reportados para as mesmas variáveis, dentro da mesma especificação e da amostra de 33 comunidades - demonstram um impacto consistente e negativo do número de comunidades tratadas sobre a variável de resultado. Isto é, quando se controla o total de comunidades participantes no mesmo raio definido para o teste. Demonstramos também o efeito a um número grande de distâncias,

\footnotetext{
22 No anexo, na parte II, registramos as variáveis que se encontravam diferentes no baseline.
} 
justamente para demonstrar a consistência do efeito negativo: não há mudança no sinal com aumento da distância. Mas é importante notar que os resultados a distâncias grandes perdem exogeneidade, já que não temos a localização e densidade de todas as regiões em distâncias elevadas nos departamentos de Matagalpa e Madriz. Os dados foram convertidos para dólares às taxas médias anuais de 2001 e $2002^{23}$. Abaixo seguem os resultados com os gastos totais em alimentos para o ano de 2001.

Gastos Totais Com Alimentos - 2001 - Tabela 1

\begin{tabular}{|c|c|c|c|c|c|c|}
\hline Variáveis & $\begin{array}{c}(1) \\
2001\end{array}$ & $\begin{array}{c}(2) \\
2001\end{array}$ & $\begin{array}{c}(3) \\
2001\end{array}$ & $\begin{array}{c}(4) \\
2001\end{array}$ & $\begin{array}{c}(5) \\
2001\end{array}$ & $\begin{array}{c}(6) \\
2001\end{array}$ \\
\hline$T_{i}$ & $\begin{array}{c}362.2^{\star * *} \\
(73.67)\end{array}$ & $\begin{array}{c}394.4^{* * *} \\
(81.98)\end{array}$ & $\begin{array}{c}347.0^{* * *} \\
(81.11)\end{array}$ & $\begin{array}{c}396.1^{* * *} \\
(88.47)\end{array}$ & $\begin{array}{c}396.9^{* * *} \\
(83.86)\end{array}$ & $\begin{array}{c}387.0^{* * *} \\
(87.18)\end{array}$ \\
\hline$N_{5 k m}^{T}$ & $\begin{array}{l}-51.81 \\
(78.09)\end{array}$ & & & & & \\
\hline$N_{10 k m}^{T}$ & & $\begin{array}{c}-144.2^{\star *} \\
(60.25)\end{array}$ & & & & \\
\hline$N_{15 k m}^{T}$ & & & $\begin{array}{l}-33.04 \\
(33.03)\end{array}$ & & & \\
\hline$N_{20 \mathrm{~km}}^{T}$ & & & & $\begin{array}{l}-44.47^{*} \\
(23.45)\end{array}$ & & \\
\hline$N_{25 k m}^{T}$ & & & & & $\begin{array}{c}-50.16^{* *} \\
(21.02)\end{array}$ & \\
\hline$N_{30 k m}^{T}$ & & & & & & $\begin{array}{c}-41.20^{* *} \\
(19.45)\end{array}$ \\
\hline Observações & 1,110 & 1,110 & 1,110 & 1,110 & 1,110 & 1,110 \\
\hline
\end{tabular}

Como se observa, o impacto é alto sobretudo para o raio de $10 \mathrm{~km}$ : o efeito de spillover alcança -144.2 dólares. Trata-se de um impacto relevante ao se considerar que o gasto total médio com alimentos no ano de 2001 foi de US\$ 1012,88 para a amostra usada - usamos aqui as mesmas taxas de câmbio usadas para as variáveis dependentes testadas. Abaixo, na Tabela 2, verificamos uma resposta mais significante, com -158.2 dólares de spillover aos 10 km e significante. Para efeitos de comparação, temos US\$ 918,16 como sendo o gasto total em alimentos no ano de 2002 para a amostra usada

\footnotetext{
${ }^{23}$ As taxas foram as disponibilizadas em tabela pelo Banco Central da Nicarágua. Disponíveis na bibliografia deste trabalho.
} 
Gastos Totais Com Alimentos - 2002 - Tabela 2

\begin{tabular}{|c|c|c|c|c|c|c|}
\hline Variáveis & $\begin{array}{c}(1) \\
2002 \\
\end{array}$ & $\begin{array}{c}(2) \\
2002 \\
\end{array}$ & $\begin{array}{c}(3) \\
2002 \\
\end{array}$ & $\begin{array}{c}(4) \\
2002 \\
\end{array}$ & $\begin{array}{c}(5) \\
2002 \\
\end{array}$ & $\begin{array}{c}(6) \\
2002 \\
\end{array}$ \\
\hline$T_{i}$ & $\begin{array}{c}137.1 \\
(85.77)\end{array}$ & $\begin{array}{c}206.2^{* * *} \\
(71.03)\end{array}$ & $\begin{array}{l}158.6^{* *} \\
(72.87)\end{array}$ & $\begin{array}{c}211.2^{* * *} \\
(72.12)\end{array}$ & $\begin{array}{c}204.9^{* * *} \\
(63.83)\end{array}$ & $\begin{array}{c}197.4^{* * *} \\
(65.21)\end{array}$ \\
\hline$N_{5 k m}^{T}$ & $\begin{array}{l}-31.28 \\
(58.29)\end{array}$ & & & & & \\
\hline$N_{10 \mathrm{~km}}^{T}$ & & $\begin{array}{c}-158.2^{* * *} \\
(51.68)\end{array}$ & & & & \\
\hline$N_{15 \mathrm{~km}}^{T}$ & & & $\begin{array}{c}-74.15^{* * *} \\
(21.12)\end{array}$ & & & \\
\hline$N_{20 k m}^{T}$ & & & & $\begin{array}{c}-80.24^{* * *} \\
(19.45)\end{array}$ & & \\
\hline$N_{25 k m}^{T}$ & & & & & $\begin{array}{c}-70.76^{* * *} \\
(18.35)\end{array}$ & \\
\hline$N_{30 k m}^{T}$ & & & & & & $\begin{array}{c}-61.77^{* * *} \\
(18.31)\end{array}$ \\
\hline Observações & 1,081 & 1,081 & 1,081 & 1,081 & 1,081 & 1,081 \\
\hline
\end{tabular}

Abaixo reportamos os efeitos na participação dos gastos em alimentos para os mesmos anos de 2000 e 2001. Deve-se notar a alta proporção dos gastos em alimentos nos gastos totais, que fica próxima a $70 \%$ na média de todas as comunidades - Maluccio e Flores (2004) reportam um aumento da participação do gasto em alimentos, sobre os gastos totais, nas comunidades tratadas, mas a proporção ainda segue próxima. Em 2001, conforme a tabela 3 , verificamos um efeito relevante de spillover somente para o raio de $10 \mathrm{~km}$, mas o efeito mantém-se consistentemente negativo para todas as distâncias. 
Participação dos Alimentos nos Gastos - 2001 - Tabela 3

\begin{tabular}{|c|c|c|c|c|c|c|}
\hline Variáveis & $\begin{array}{c}(1) \\
2001\end{array}$ & $\begin{array}{c}(2) \\
2001\end{array}$ & $\begin{array}{c}(3) \\
2001\end{array}$ & $\begin{array}{c}(4) \\
2001\end{array}$ & $\begin{array}{c}(5) \\
2001\end{array}$ & $\begin{array}{c}(6) \\
2001\end{array}$ \\
\hline$T_{i}$ & $\begin{array}{c}0.0483^{* * *} \\
(0.0138)\end{array}$ & $\begin{array}{c}0.0543^{* * *} \\
(0.0123)\end{array}$ & $\begin{array}{c}0.0483^{* * *} \\
(0.0133)\end{array}$ & $\begin{array}{c}0.0555^{\star * *} \\
(0.0132)\end{array}$ & $\begin{array}{c}0.0528^{* * *} \\
(0.0127)\end{array}$ & $\begin{array}{c}0.0489 * * * \\
(0.0133)\end{array}$ \\
\hline$N_{5 \mathrm{~km}}^{T}$ & $\begin{array}{r}-0.00519 \\
(0.0122)\end{array}$ & & & & & \\
\hline$N_{10 \mathrm{~km}}^{T}$ & & $\begin{array}{l}-0.0209^{*} \\
(0.0116)\end{array}$ & & & & \\
\hline$N_{15 \mathrm{~km}}^{T}$ & & & $\begin{array}{l}-0.00517 \\
(0.00573)\end{array}$ & & & \\
\hline$N_{20 \mathrm{~km}}^{T}$ & & & & $\begin{array}{l}-0.00732^{*} \\
(0.00429)\end{array}$ & & \\
\hline$N_{25 \mathrm{~km}}^{T}$ & & & & & $\begin{array}{l}-0.0106^{\star *} \\
(0.00386)\end{array}$ & \\
\hline$N_{30 \mathrm{~km}}^{T}$ & & & & & & $\begin{array}{c}-0.0114^{* * *} \\
(0.00368)\end{array}$ \\
\hline Observações & 1,110 & 1,110 & 1,110 & 1,110 & 1,110 & 1,110 \\
\hline
\end{tabular}

Na tabela 4 alcança-se um resultado mais interessante e a uma distância mais intuitiva: à distância de $5 \mathrm{~km}$ há um resultado negativo e extremamente significante para a mudança na participação no gasto em alimentos. Reparese que o efeito de spillover derruba em mais da metade o efeito de tratamento de $T_{i}$ à distância de $5 \mathrm{~km}$, sendo assim um efeito alto e relevante. Trata-se também do caso em que a variabilidade de $N_{d}^{T}$ causa um impacto relevante em todas as distâncias apresentadas. 


\section{Participação dos Alimentos nos Gastos Totais - 2002 - Tabela 4}

\begin{tabular}{|c|c|c|c|c|c|c|}
\hline Variáveis & $\begin{array}{c}(1) \\
2002 \\
\end{array}$ & $\begin{array}{c}(2) \\
2002 \\
\end{array}$ & $\begin{array}{c}(3) \\
2002 \\
\end{array}$ & $\begin{array}{c}(4) \\
2002 \\
\end{array}$ & $\begin{array}{c}(5) \\
2002 \\
\end{array}$ & $\begin{array}{c}6) \\
2002 \\
\end{array}$ \\
\hline$T_{i}$ & $\begin{array}{l}0.0358^{* * *} \\
(0.00912)\end{array}$ & $\begin{array}{c}0.0445^{* * *} \\
(0.0103)\end{array}$ & $\begin{array}{c}0.0404^{* * *} \\
(0.0101)\end{array}$ & $\begin{array}{c}0.0443^{* * *} \\
(0.0102)\end{array}$ & $\begin{array}{c}0.0436^{* * *} \\
(0.0102)\end{array}$ & $\begin{array}{c}0.0448^{* * *} \\
(0.0104)\end{array}$ \\
\hline$N_{5 k m}^{T}$ & $\begin{array}{c}-0.0234^{* * *} \\
(0.00748)\end{array}$ & & & & & \\
\hline$N_{10 \mathrm{~km}}^{T}$ & & $\begin{array}{l}-0.0124^{*} \\
(0.00669)\end{array}$ & & & & \\
\hline$N_{15 \mathrm{~km}}^{T}$ & & & $\begin{array}{c}-0.00831^{* * *} \\
(0.00238)\end{array}$ & & & \\
\hline$N_{20 \mathrm{~km}}^{T}$ & & & & $\begin{array}{c}-0.00630^{* *} \\
(0.00261)\end{array}$ & & \\
\hline$N_{25 \mathrm{~km}}^{T}$ & & & & & $\begin{array}{l}-0.00417^{*} \\
(0.00211)\end{array}$ & \\
\hline$N_{30 \mathrm{~km}}^{T}$ & & & & & & $\begin{array}{l}-0.00306 \\
(0.00203)\end{array}$ \\
\hline Observações & 1,081 & 1,081 & 1,081 & 1,081 & 1,081 & 1,081 \\
\hline
\end{tabular}

O fato consistente de que há um impacto negativo sobre as variáveis explicadas do número de vilas tratadas em um raio $d$ nos permite perguntar sobre a possibilidade de uma inelasticidade na oferta da região, pois, se existe esse efeito, poderíamos amparar uma justificativa para os efeitos negativos. Supondo um mercado comum na proximidade, o efeito dos tratados poderia aumentar a demanda e, por sua vez, aumentar preços e diminuir o consumo de alimentos se houver uma oferta inelástica nos anos avaliados - esses seriam efeitos de equilíbrio geral que ainda não possuímos dados para testar.

Há ainda o fato reportado por Maluccio (2005) de que houve uma crise na região, que foi afetada pela queda de preços do café, assim como através de uma estiagem severa durante o período de 2001. A julgar pela queda nos gastos entre 2000-2001 e 2000-2002 compreendida por Maluccio (2005), poderíamos supor uma queda nos salários, já que não houve diminuição de horas trabalhadas, isto é, talvez houve uma diminuição do produto marginal uma queda na "oferta". Dessa forma, os efeitos indiretos poderiam ser 
asseverados com o aumento dos gastos em comunidades tratadas e com a contração da "oferta", o que também resultaria em preços ainda maiores.

Sem reportar neste trabalho, foram rodadas regressões adicionais somente para a regiões de Matagalpa, onde se localizam todas as comunidades relacionadas à produção de café, e de Madriz. Acha-se resultados não muito diferentes dos que são reportados aqui para a região de Matagalpa, apenas com os coeficientes um pouco mais fortes - a região concentra a maioria das comunidades. No caso de Madriz temos um fato curioso: os efeitos dos spillovers são positivos em alguns casos. Esse resultado talvez aponte o caminho para estudar os efeitos específicos na região de Matagalpa, sabendo da crise relacionada ao preço do café e que afetou a região, fato reportado em Maluccio (2005).

Segue, assim, pela amostra disponível, a constatação da possibilidadede spillovers afetando as famílias avaliadas no programa e, em especial, os gastos com os alimentos nos anos de 2001 e 2002.

\section{Conclusões e Considerações Finais}

A notar pelos trabalhos citados neste texto e pelos resultados obtidos, compreende-se a importância para o controle dos efeitos de spillovers. Como já foi dito, pode ser irrazoável supor que não acontecerão efeitos indiretos, spillovers effects sobre vizinhos participantes ou não-participantes da avaliação do programa durante sua implementação.

Com o resultado obtido, pretende-se contribuir com os estudos sobre o programa RPS e, principalmente, com os resultados de Maluccio e Flores 
(2004) e Maluccio (2005). Os estudos avaliaram, respectivamente, os gastos das famílias durante os dois anos de avaliação do RPS -- totais e com alimentos, dentre outros aspectos avaliados do programa -- e o impacto contra-cíclico do programa diante da queda dos preços do café.

Contudo, o trabalho aponta para uma maior investigação dos efeitos externos pela proximidade das regiões; em especial, sobre a possibilidade de efeitos de equilíbrio geral. Sabendo da pobreza na região e da crise ocorrida na região de Matagalpa, é possível que esses sejam fatos que ajudem a fechar a história sobre os efeitos mais amplos do programa RPS.

\section{Bibliografia}

ARCIA, GABRIEL. Proyecto de Red de Protección Social: Focalización de lafasepiloto. Relatóriosubmetidoaolnter-American Development Bank.Washinton, DC. 1999.

ANGELUCCI, MANUELA. DE GIORGI, GIACOMO. Indirect Effects of an Aid Program: How Do Cash Transfers Affect Ineligibles' Consumption? American Economic Review vol . 99 (1), p. 486-508. 2009.

BANCO CENTRAL DE NICARAGUA. Deslizamiento diario del tipo de cambio oficial delcordoba versus US dolar 2001. Disponível em <http://www.bcn.gob.ni/estadisticas/mercados_cambiarios/tipo_cambio/cordo ba_dolar/cambio_historico/9401/tipcamb2001.pdf> Acessadoem 7 de Novembro de 2014. 
BANCO CENTRAL DE NICARAGUA. Deslizamiento diario del tipo de cambio oficial delcordoba versus US dolar 2001. Disponível em <http://www.bcn.gob.ni/estadisticas/mercados_cambiarios/tipo_cambio/cordo ba_dolar/cambio_historico/2002/tipcamb2002.pdf> Acessado em 7 de Novembro de 2014.

BANCO CENTRAL DE NICARAGUA. Deslizamiento diário del tipo de cambio oficial delcordoba versus US dolar 2000. Disponível em <http://www.bcn.gob.ni/estadisticas/mercados_cambiarios/tipo_cambio/cordo ba_dolar/cambio_historico/9401/2000.pdf> Acessado em 7 de Novembro de 2014

BANCO MUNDIAL. Poverty reduction and growth: virtuous and vicious circles. Washington, DC: Banco Mundial. 2006. 238 p. 2006.

BOBBA, MATTEO. GIGNOUX, JÉRÉMIE. Spatial Externalities and Social Multipliers of Schooling Interventions, Working Paper. p.1-36. 2009.

BOBONIS, GUSTAVO J. FINAN, FREDERICO. Neighborhood Peer Effects in Secondary School Enrollment Decisions. Review of Economics and Statistics vol. 91(4), p. 697-716. 2009.

DIVA-GIS: FREE, SIMPLE AND EFFECTIVE. Disponível em <http://divagis.org/> Acessado em 7 Novembro de 2014.

DUFLO, ESTHER. SAEZ, EMMANUEL. The Role Of Information And Social Interactions In Retirement Plan Decisions: Evidence From A Randomized Experiment. The Quarterly Journal of Economics, MIT Press.vol.118(3), p. 815-842, 2003. 
FIZBEIN, A. SCHADY, N. Conditional Cash Transfers: Reducing present and future poverty. Washington, DC: World Bank. p. 1-361. 2010. Disponível em <https://openknowledge.worldbank.org/bitstream/handle/10986/2597/476030 PUB0Cond1010fficial0Use00nly1.pdf?sequence=1> Acessado em 25 de outubro de 2014.

GIGNOUX, JÉRÉMIE. Spillover of Conditional Cash Transfer across Localities: Evidence from Progresa, Working Paper. Paris: Laboratoire d'Economie Appliquee, INRA, 2009.

GITTER, SETH RICHARD. BARHAM, BRADFORD. Conditional Cash Transfers, Shocks, and School Enrolment in Nicaragua. Journal of Development Studies, Taylor and Francis Journals.vol.45(10), pages 17471767. 2009.

GITTER, SETH RICHARD. CALDES, NATALIA. 2010. Crisis, Food Security, and Conditional Cash Transfers in Nicaragua. Working Papers 2010-07, Towson University, Department of Economics. 2010

GITTER, SETH RICHARD. MANLEY, JAMES. Bradford L. Barham. EarlyChildhood Nutrition and Educational Conditional Cash Transfer Programmes. Journal of Development Studies, Taylor and Francis Journals, vol. 49(10), p. 1397-1411, 2013.

LEHMANN, CHRISTIAN. Benefeting Without Receiving Money? Externalities of Conditional Cash Transfer Programmes on Schooling, Health and The Village Economy. International Center for Inclusive Growth. Research Brief. № 13. 2010.

KATZ, LAWRENCE F. KLING, JEFFREY R. LIEBMAN, JEFFREY B. Moving To Opportunity In Boston: Early Results Of A Randomized Mobility Experiment. The Quarterly Journal of Economics, MIT Press. vol. 116(2), p. 607-654, 2001. 
MALUCCIO, JOHN A. FLORES, RAFAEL. Impact evaluation of a conditional cash transfer program: the Nicaraguan Red de Protección Social. International Food Policy Research Institute (IFPRI). Research reports 141, p. 1-78, 2004.

MALUCCIO, JOHN A.,2005. Coping with the "coffee crisis" in Central America: The Role of the Nicaraguan Red de Protección Social. International Food Policy Research Institute (IFPRI). FCND discussion papers 188, p. 157. 2005.

MIGUEL, EDWARD. KREMER, MICHAEL. Worms: Identifying Impacts on Education and Health in the Presence of Treatment Externalities. Econometrica, vol. 72(1), p. 159-217. 2004.

NICARAGUA: REDS DE PROTECCIÓN EVALUATION DATASET, 20002002.International Food Policy Research Institute (IFPRI), Washington, D.C.. 2005. Disponível em < http://www.ifpri.org/dataset/nicaragua>

NICARAGUAN RPS EVALUATION DATA. Overview and Description of Data Files. International Food Policy Research Institute. p. 1-33. 2005

NOAA History: Geodetic Surveying 1940-1990. Disponível em <http://www.history.noaa.gov/stories tales/geod1.html> acessadoem 5 de novembro de 2014

PALMA, JULIET. URZÚA, RAÚL. Anti-poverty Policies and Citizenry: the “Chile Solidario" Experience. Policy Papers N N 12. Paris: UNESCO. 2005.

RUBIN, DONALD. Statistics and Causal Inference: Comment: Which Ifs Have Causal Answer. Journal of the American Statistical Association, Vol. 81, $\mathrm{N}^{\circ}$ 396. p. 961-962. 1986. 
SACERDOTE, BRUCE. Peer Effects With Random Assignment: Results For Dartmouth Roommates," The Quarterly Journal of Economics, MIT Press. vol. 116(2), p. 681-704, 2001.

THE ECONOMIST. Control Freaks: Are "randomised evaluations" a better way of doing aid and development policy? Julho de 2008.Disponívelem<http://www.economist.com/node/11535592>Acessadoem 5 de Novembro de 2014. 


\section{Apêndice - Parte I - Resultados Adicionais}

Apresentamos alguns resultados adicionais para dar conta do fato de não possuímos um mapa com todas as comunidades e densidades das regiões de Madriz e Matagalpa. Apresentar os efeitos para distâncias menores envolve menos chances de erros de controle de densidade e talvez nos dê resultados mais robustos.

Existe, porém, uma manipulação adicional dos dados nestes resultados adicionais. Como há variabilidade no tamanho das comunidades, ponderamos o número de famílias em cada comunidade pela média de 236 famílias, de forma que o valor de 1 para uma variável do número comunidades (as novas versões de $N_{d i}$ e $N_{d i}$ ) fosse representativo de 236 famílias. Por exemplo, se a comunidade que aparece em uma distância $d$ possui um tamanho menor do que 236 famílias, a variável de número de comunidades adicionaria um valor ponderado por 236 famílias e, logo, menor do que 1. O mesmo é feito para a variável que descreve o número de comunidades tratadas, naturalmente. Há a distinção, porém, que a variável $N_{d i}$ considera o pequeno número de famílias não-participantes das comunidades tratadas, o que não consideramos em $N_{d i}^{T}$ quando 0 ponderamos pela média de 236 família. Seguem os resultados para pequenas distâncias da Tabela 5:

\section{Gastos Totais Com Alimentos - 2001 e 2002 - Tabela 5}

\begin{tabular}{|c|c|c|c|c|c|c|}
\hline Variáveis & $\begin{array}{c}(1) \\
2001\end{array}$ & $\begin{array}{c}(2) \\
2001\end{array}$ & $\begin{array}{c}(3) \\
2001\end{array}$ & $\begin{array}{c}(4) \\
2002\end{array}$ & $\begin{array}{c}(5) \\
2002\end{array}$ & $\begin{array}{c}(6) \\
2002\end{array}$ \\
\hline$T_{i}$ & $\begin{array}{c}321.2^{* * *} \\
(79.42)\end{array}$ & $\begin{array}{c}311.5^{\star * *} \\
(74.09)\end{array}$ & $\begin{array}{c}294.5^{\star * *} \\
(74.48)\end{array}$ & $\begin{array}{c}129.7 \\
(81.18)\end{array}$ & $\begin{array}{c}93.55 \\
(80.57)\end{array}$ & $\begin{array}{c}86.66 \\
(82.32)\end{array}$ \\
\hline$N_{1 \mathrm{~km}}^{T}$ & $\begin{array}{c}-264.5^{\star * *} \\
(80.47)\end{array}$ & & & $\begin{array}{c}103.5 \\
(79.75)\end{array}$ & & \\
\hline$N_{2 k m}^{T}$ & & $\begin{array}{l}-247.0^{*} \\
(143.6)\end{array}$ & & & $\begin{array}{l}-173.3 \\
(144.0)\end{array}$ & \\
\hline$N_{3 k m}^{T}$ & & & $\begin{array}{l}-278.6^{*} \\
(144.4)\end{array}$ & & & $\begin{array}{l}-171.5 \\
(144.3)\end{array}$ \\
\hline Observações & 1,110 & 1,110 & 1,110 & 1,081 & 1,081 & 1,081 \\
\hline
\end{tabular}


Reportamos o efeito à distância de $1 \mathrm{~km}$, mas há somente duas comunidades nesse raio (uma comunidade está no raio da outra, naturalmente). Em $3 \mathrm{~km}$, encontramos mais variabilidade, com dez comunidades com pelo menos uma outra em seu raio e quatro são tratadas dessas comunidades. Pela significância, o coeficiente a $3 \mathrm{~km}$ traz mais robustez ao spillover negativo verificado neste trabalho. Abaixo na Tabela II demonstramos o resultado per capita dos gastos totais em alimentos, que apresenta resultados mais significantes. É interessante também a magnitude do efeito, deixando o efeito de tratamento com o spillover extremamente pequeno ou negativo (ao subtrairmos o efeito de $N_{d}^{T}$ de $T_{i}$ ) no caso da Tabela II.

Gastos Totais Com Alimentos per capita - 2001 e 2002 - Tabela 6

\begin{tabular}{|c|c|c|c|c|c|c|}
\hline Variáveis & $\begin{array}{c}(1) \\
2001 \\
\end{array}$ & $\begin{array}{c}(2) \\
2001 \\
\end{array}$ & $\begin{array}{c}(3) \\
2001 \\
\end{array}$ & $\begin{array}{c}(4) \\
2002 \\
\end{array}$ & $\begin{array}{c}(5) \\
2002 \\
\end{array}$ & $\begin{array}{c}(6) \\
2002 \\
\end{array}$ \\
\hline$T_{i}$ & $\begin{array}{c}71.11^{* * *} \\
(17.56)\end{array}$ & $\begin{array}{c}72.94^{\star * *} \\
(15.32)\end{array}$ & $\begin{array}{c}69.12^{* * *} \\
(15.12)\end{array}$ & $\begin{array}{c}35.30^{*} \\
(18.34)\end{array}$ & $\begin{array}{l}34.17^{\star *} \\
(16.54)\end{array}$ & $\begin{array}{c}33.42^{*} \\
(16.70)\end{array}$ \\
\hline$N_{1 k m}^{T}$ & $\begin{array}{c}-143.1^{* * *} \\
(20.75)\end{array}$ & & & $\begin{array}{c}-89.03^{* * *} \\
(21.55)\end{array}$ & & \\
\hline$N_{2 k m}^{T}$ & & $\begin{array}{c}-69.87^{* *} \\
(34.14)\end{array}$ & & & $\begin{array}{l}-53.49 \\
(36.93)\end{array}$ & \\
\hline$N_{3 k m}^{T}$ & & & $\begin{array}{c}-75.62^{* *} \\
(32.01)\end{array}$ & & & $\begin{array}{l}-45.54 \\
(35.98)\end{array}$ \\
\hline Observações & 1,110 & 1,110 & 1,110 & 1,081 & 1,081 & 1,081 \\
\hline
\end{tabular}

Em 2001, conforme a tabela III, verificamos um efeito relevante de spillover na participação dos gastos com alimentos até a distância de $3 \mathrm{~km}$. É importante reparar que o efeito de tratamento (com o spillover) se torna negativo: o efeito de comunidades tratadas nessas distâncias supera o efeito positivo de $T_{i}$. Em 2002 há diminuição do tamanho do spillover e da significância de alguns resultados, mas o impacto segue na mesma direção. 
Participação dos Alimentos nos Gastos - 2001 e 2002 - Tabela 7

\begin{tabular}{|c|c|c|c|c|c|c|}
\hline Variáveis & $\begin{array}{c}(1) \\
2001 \\
\end{array}$ & $\begin{array}{c}(2) \\
2001 \\
\end{array}$ & $\begin{array}{c}(3) \\
2001 \\
\end{array}$ & $\begin{array}{c}(4) \\
2002 \\
\end{array}$ & $\begin{array}{c}(5) \\
2002 \\
\end{array}$ & $\begin{array}{c}(6) \\
2002 \\
\end{array}$ \\
\hline$T_{i}$ & $\begin{array}{c}0.0365^{* *} \\
(0.0149)\end{array}$ & $\begin{array}{c}0.0351 * * \\
(0.0151)\end{array}$ & $\begin{array}{c}0.0355^{* *} \\
(0.0159)\end{array}$ & $\begin{array}{c}0.0368 * * * \\
(0.0116)\end{array}$ & $\begin{array}{c}0.0326 * * * \\
(0.0103)\end{array}$ & $\begin{array}{c}0.0317^{* * *} \\
(0.0107)\end{array}$ \\
\hline$N_{1 k m}^{T}$ & $\begin{array}{c}-0.104 * * * \\
(0.0157)\end{array}$ & & & $\begin{array}{l}-0.0122 \\
(0.0140)\end{array}$ & & \\
\hline$N_{2 k m}^{T}$ & & $\begin{array}{c}-0.0592 * * * \\
(0.0191)\end{array}$ & & & $\begin{array}{l}-0.0345^{*} \\
(0.0194)\end{array}$ & \\
\hline$N_{3 k m}^{T}$ & & & $\begin{array}{c}-0.0448 * * \\
(0.0215)\end{array}$ & & & $\begin{array}{l}-0.0331^{*} \\
(0.0185)\end{array}$ \\
\hline Observações & 1,110 & 1,110 & 1,110 & 1,081 & 1,081 & 1,081 \\
\hline
\end{tabular}

Abaixo, na figura I, observamos um pouco da variabilidade do número de comunidades tratadas $\left(N_{d}^{T}\right)$ na medida em que aumentamos a distância. Trata-se da variabilidade do primeiro "conjunto" de comunidades, o primeiro cluster; depois da faixa dos $20 \mathrm{~km}$, as comunidades passam a ter um número próximo de comunidades tratadas. Acima de $50 \mathrm{~km}$, há aumento da variabilidade mas não julgamos ser um relato interessante. Nas regiões de curta distância e de interesse deste trabalho, observamos como a variabilidade só aumenta.

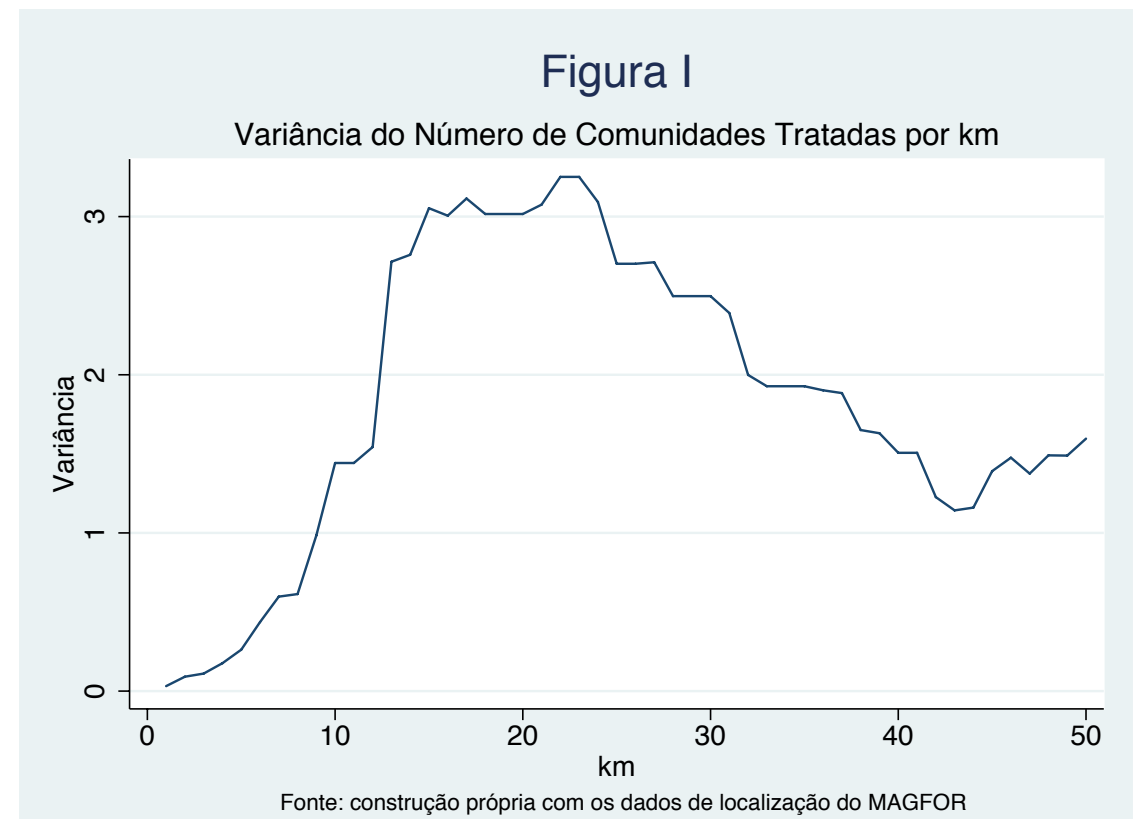




\section{Apêndice - Parte II - Dados do Baseline}

Na tabela I cruzamos os dados das famílias usadas na amostra de trabalho com o censo realizado, pré-programa, com 505 observações para o grupo de tratamento e 703 para o de controle das 33 localizações usadas neste trabalho. Para a comparação das médias usamos somente um teste-t de student e apresentamos os p-valores para o teste bilateral. Todas as variáveis foram convertidas para dólares a uma média da taxa de câmbio anual de $2000^{24}$. Como detalhado anteriormente, todas as variáveis que se encontraram diferentes no baseline foram inseridas como variáveis de controle na regressão estatística deste trabalho, mesmo aquelas de pequena diferença. À frente descrevemos os resultados obtidos ao se testar a diferença entre as variáveis no baseline.

Não acreditamos que a diferença em variáveis como o gasto em saúde da mãe produza grandes impactos em nossas estimativas, embora seja controlada. Em luz, a diferença dos gastos no baseline é aproximadamente de dois dólares e não parece ser, assim, uma diferença de grande impacto também. Contudo há uma diferença grande e bastante significante nos gastos totais em saúde entre as comunidades de controle e de tratamento e que se deve ter em consideração.

Abaixo, ainda na Tabela I, detalhamos as diferenças em tamanho de propriedade em metros quadrados. Trata-se de uma diferença visivelmente grande em nossa amostra e que é controlada nos testes deste trabalho.

As variáveis que nomeamos "Arcia 1" e "Arcia 2" são os dois grupos separados em "Prioridade 1" e "Prioridade 2" - o grupo de "Prioridade 1", pelo

${ }^{24}$ A tabela com dados de conversão para 2000 segue disponível na bibliografia 
índice de marginalidade descrito anteriormente no trabalho, tem o score acima de 85 pontos e é o mais pobre e o de "Prioridade 2", sendo relativamente menos pobre em relação ao de "Prioridade 1", com os scores entre 70 pontos e 85 pontos. A notar, na fase em que se visava definir as regiões do RPS, foram escolhidas as comunidades que somente continham os dois tipos prioridade listadas acima. Fazemos uma comparação dos gastos totais entre os dois grupos, que estão presentes nas comunidades tratadas e de controle.

Na tabela II a variável de bens duráveis contém respostas para os bens: cozinha, gravadoras de fita cassete e ventiladores. Essas variáveis estão presentes na base em forma binária para a pergunta sobre se a família em questão possui esses bens - "sim" sendo representado por 1 e "não" por 2. Testando essas variáveis de forma desagregada, não encontramos diferenças significantes na amostra usada. No caso das variáveis específicas de veículos e ar-condicionado, que estão presentes na base de dados original do censo do RPS, não encontramos nenhuma observação com uma resposta diferente de "não" em nossa base. Para efeitos de resumo, apresentamos uma versão agregada, que também não produz uma diferença significante.

Tabela I - Dados do Censo Pré-RPS

\begin{tabular}{|l|r|r|r|}
\hline Variáveis (Censo) & $\begin{array}{c}\text { Média } \\
\text { (Controle) }\end{array}$ & $\begin{array}{c}\text { Média } \\
\text { (Tratamento) }\end{array}$ & P-valor $^{*}$ \\
\hline Número de Quartos & 1.46 & 1.48 & 0.733 \\
\hline Bens Duráveis & 5.77 & 5.75 & 0.607 \\
\hline Propriedade (em m ${ }^{2}$ ) & 14189.80 & 12258.18 & 0.076 \\
\hline Idade do Chefe da Casa & 43.64 & 45.07 & 0.152 \\
\hline $\begin{array}{l}\text { Anos de Estudo do Chefe da } \\
\text { Casa }\end{array}$ & 1.79 & 1.73 & 0.658 \\
\hline Anos de Estudo de Adultos & 2.17 & 2.22 & 0.665 \\
\hline Número de Crianças (<5anos) & 0.93 & 0.86 & 0.276 \\
\hline
\end{tabular}

Nota: 505 observações de tratamento e 703 de controle. Uso do teste-t bilateral para testar a significância da diferença das médias. As médias foram testadas com os fatores de expansão da amostra. 
Tabela II - Dados do Baseline em coletados de Agosto a Setembro 2000 - Dados de Gastos

\begin{tabular}{|c|c|c|c|}
\hline $\begin{array}{l}\text { Variáveis } \\
\text { (Gastos) }\end{array}$ & $\begin{array}{c}\text { Média } \\
\text { (Controle) }\end{array}$ & $\begin{array}{c}\text { Média } \\
\text { (Tratamento) }\end{array}$ & P-Valor \\
\hline Pessoas & 6.13 & 6.11 & 0.74 \\
\hline $\begin{array}{l}\text { Gasto Total com } \\
\text { Alimentos }\end{array}$ & 1145.61 & 1111.47 & 0.46 \\
\hline $\begin{array}{l}\text { Gasto total com Não- } \\
\text { Alimentos }\end{array}$ & 180.79 & 179.97 & 0.95 \\
\hline Agua & 0.21 & .24 & 0.59 \\
\hline Combustível & 3.17 & 3.01 & 0.88 \\
\hline Educação & 23.14 & 24.12 & 0.77 \\
\hline Eletricidade & 6.58 & 6.59 & 0.99 \\
\hline Luz & 19.95 & 17.36 & 0.09 \\
\hline Saúde & 49.18 & 69.12 & 0.00 \\
\hline Saúde da Mãe & 2.36 & 1.05 & 0.02 \\
\hline Bens Duráveis & 11.19 & 11.01 & 0.93 \\
\hline Gastos Totais & 1600.87 & 1580.59 & 0.74 \\
\hline $\begin{array}{l}\text { Gastos Totais per } \\
\text { capita }\end{array}$ & 306.18 & 303.33 & 0.83 \\
\hline $\begin{array}{l}\text { Participação de } \\
\text { Alimentos no Gasto }\end{array}$ & 0.71 & 0.70 & 0.19 \\
\hline $\begin{array}{l}\text { Gastos com } \\
\text { Alimentos per capita }\end{array}$ & 215.53 & 210.04 & 0.57 \\
\hline $\begin{array}{l}\text { Arcia1 (Gastos } \\
\text { Totais) }\end{array}$ & 1269.11 & 1259.10 & 0.91 \\
\hline $\begin{array}{l}\text { Arcia2 (Gastos } \\
\text { Totais) }\end{array}$ & 1661.79 & 1636.77 & 0.72 \\
\hline
\end{tabular}

Nota: 505 observações de tratamento e 703 de controle. Uso do teste-t bilateral para testar a significância da diferença das médias. As médias foram testadas com os fatores de expansão da amostra 


\section{Apêndice - Parte III - Mapas}

Abaixo, apresentamos um mapa para o país inteiro, para referenciar a localização das duas regiões em que se concentram as do programa RPS e um mapa mais detalhado das duas regiões, Matagalpa e Madriz. O mapa das duas regiões ainda é, possivelmente, limitado para mostrar adequadamente a localização das comunidades, pois há a possibilidade de alguma imprecisão na base. Note-se, ainda assim, a sobreposição que ocorre na localização de algumas comunidades -- é pela grande proximidade que se justifica este trabalho. O mapa também serve para demonstrar que existem claros agrupamentos de comunidades, a notar, por exemplo, na concentração que se vê em Madriz (região menor, à esquerda, no mapa separado para as duas regiões) ou em municípios de Matagalpa (região maior e à direita no mapa separado), como Ciudad Darío - o extremo leste de Matagalpa.

Os Mapas abaixo foram gerados com os dados obtidos das localizações das comunidades e com os dados dos shapefiles (GIS) presentes no site DIVAGIS e gerados através do programa Stata. Desconhecemos, por enquanto, a possibilidade de imprecisões com o método de geração dos dois mapas abaixo. 


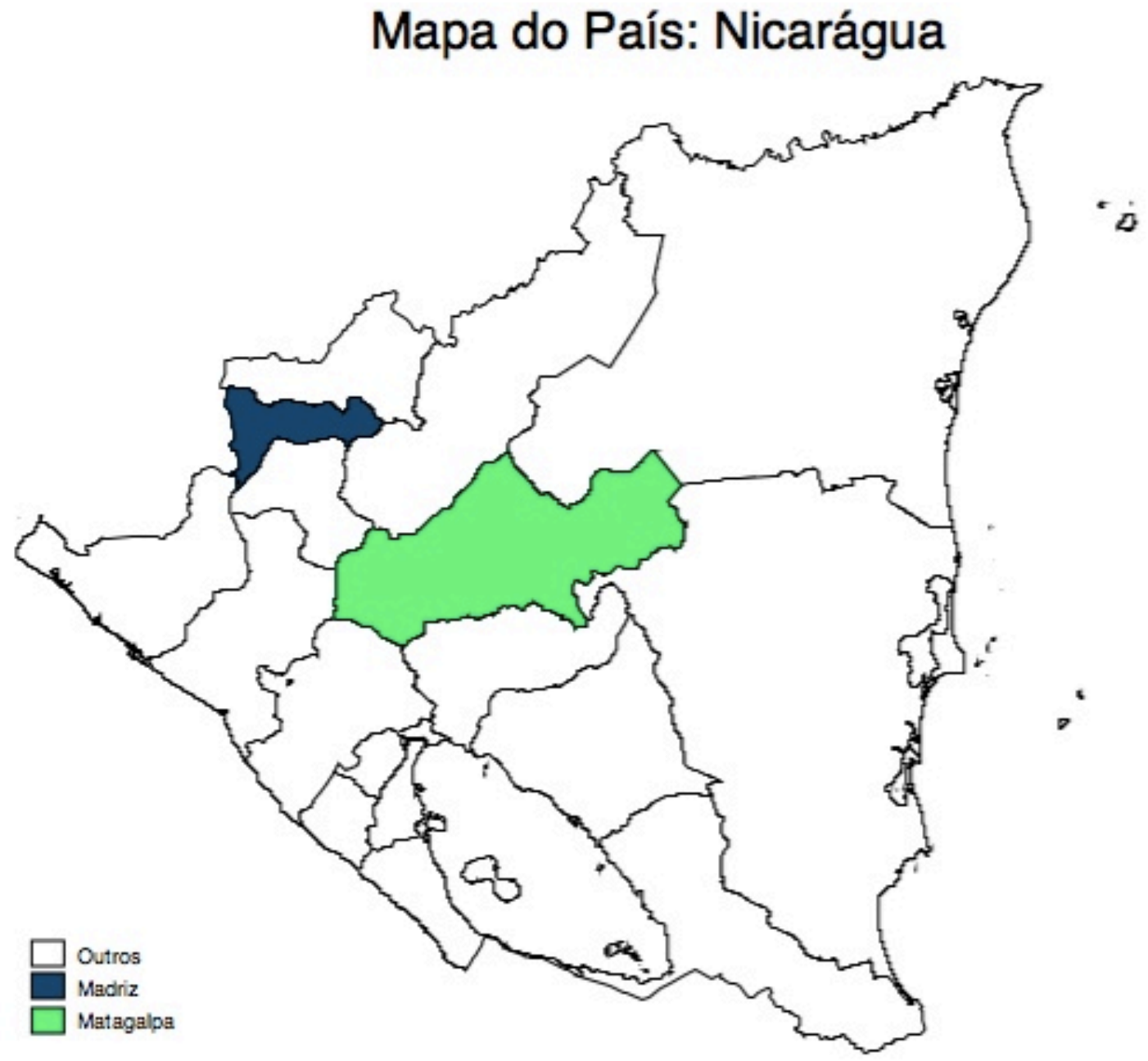




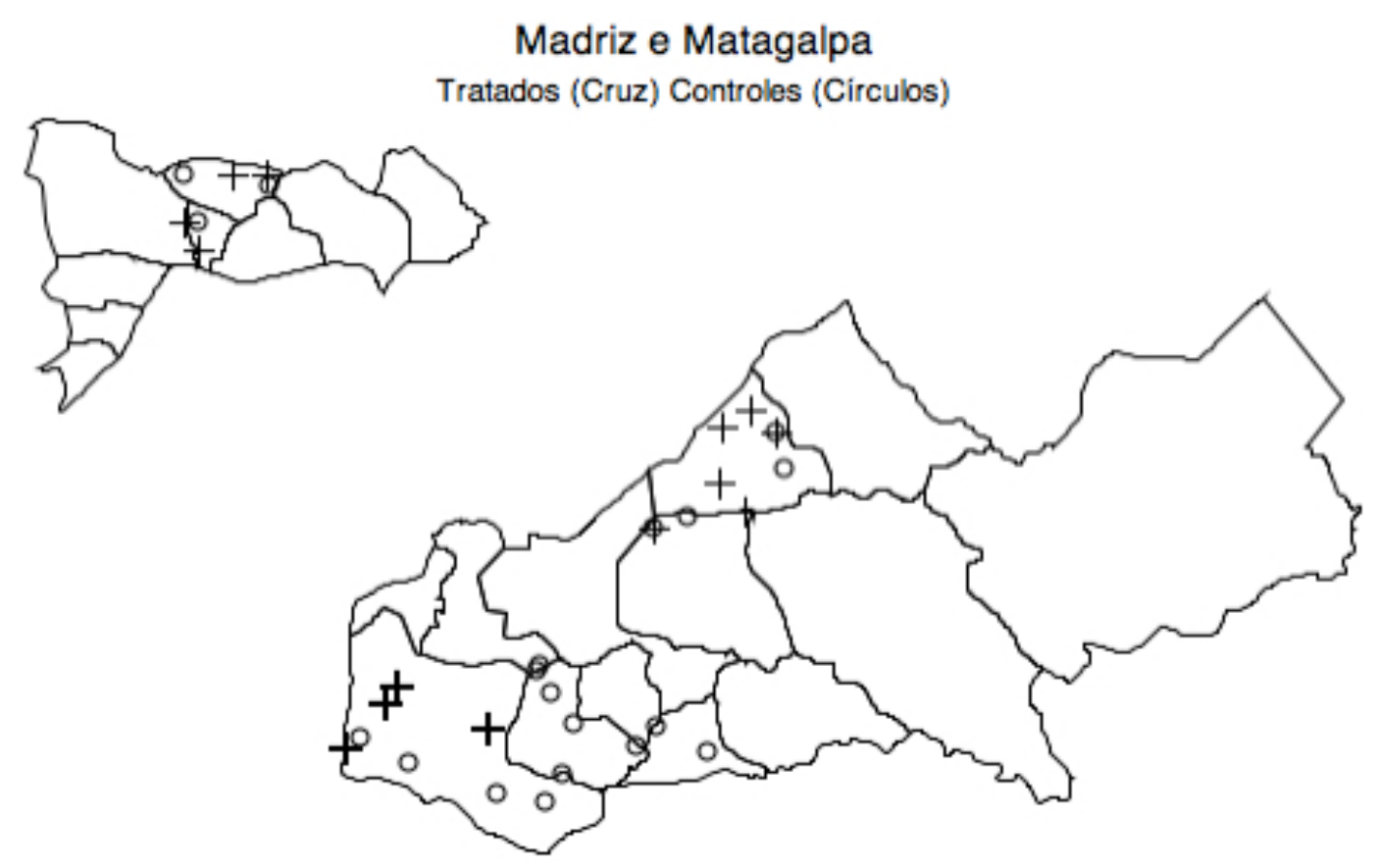

